\title{
Adult Attachment System Links With Brain Mu Opioid Receptor Availability In Vivo
}

\section{Turtonen, Otto}

2021-03

Turtonen , O , Saarinen, A, Nummenmaa , L , Tuominen , L , Tikka , M , Armio , R-L , Hautamäki , A , Laurikainen , H , Raitakari , O , Keltikangas-Järvinen , L \& Hietala , J 2021 , ' Adult Attachment System Links With Brain Mu Opioid Receptor Availability In Vivo ', Biological Psychiatry: Cognitive Neuroscience and Neuroimaging , vol. 6 , no. 3 , pp. 360-369 . https://doi.org/10.1016/j.bpsc.2020.10.013

http://hdl.handle.net/10138/335867

https://doi.org/10.1016/j.bpsc.2020.10.013

cc_by_nc_nd

acceptedVersion

Downloaded from Helda, University of Helsinki institutional repository.

This is an electronic reprint of the original article.

This reprint may differ from the original in pagination and typographic detail.

Please cite the original version. 


\section{Adult Attachment System Links with Brain $\mu$-Opioid Receptor Availability in vivo}

Running title: Attachment and $\mu$-Opioid Receptor Availability

Keywords: Attachment; Positron emission tomography; Opioid; Serotonin; Neurotransmission

Otto Turtonen $^{1 *}$, Aino Saarinen ${ }^{2,3^{*}}$, Lauri Nummenmaa ${ }^{1,4}$, Lauri Tuominen ${ }^{1,5,6}$, Maria Tikka ${ }^{5}$ Reetta-Liina Armio ${ }^{1,5}$, Airi Hautamäki ${ }^{7}$, Heikki Laurikainen ${ }^{1,5}$, Olli Raitakari ${ }^{8}$, Liisa Keltikangas-Järvinen ${ }^{3}$, and Jarmo Hietala ${ }^{1,5}$

${ }^{1}$ Turku PET Centre and Turku University Hospital, University of Turku, Turku, Finland

${ }^{2}$ Department of Psychology and Logopedics, Faculty of Medicine, University of Helsinki, Helsinki, Finland

${ }^{3}$ Research Unit of Psychology, University of Oulu, Finland

${ }^{4}$ Department of Psychology, University of Turku

${ }^{5}$ Department of Psychiatry, University of Turku and Turku University Hospital, Finland

${ }^{6}$ The Royal's Institute of Mental Health Research, Ottawa, ON K1Z 8N3, Canada

${ }^{7}$ Swedish School of Social Science, University of Helsinki, Helsinki, Finland

${ }^{8}$ Research Centre of Applied and Preventive Cardiovascular Medicine, University of Turku, Finland

*) Shared first authorship.

Correspondence to: Professor Jarmo Hietala, MD. Department of Psychiatry, University of Turku, 20700-Turku, Finland. Email: jahi@utu.fi 


\begin{abstract}
Background: Secure attachment is important in maintaining individual's health and well-being. Attachment disturbances increase the risk for developing different psychiatric disorders such as affective disorders. Yet, the neurobiological correlates of human attachment is poorly understood at the neurotransmitter level. We investigated whether adult attachment style is linked to functioning of the opioid and serotonergic systems in the human brain. Methods: We used positron emission tomography (PET) with radioligands $\left[{ }^{11} \mathrm{C}\right]$ carfentanil and $\left[{ }^{11} \mathrm{C}\right]$ MADAM to quantify $\mu-$ opioid receptor $(\mathrm{N}=39)$ and serotonin transporter $(\mathrm{N}=37)$ availability in volunteers with no current psychiatric disorders. Attachment style was determined according to the Dynamic-Maturational Model of attachment and adaptation with the structured Adult Attachment Interview (AAI). Results: Secure attachment was associated with higher $\mu$-opioid receptor availability in the hippocampus, amygdala, thalamus and prefrontal cortex when compared to insecure (i.e., avoidant or ambivalent groups combined) attachment. In contrast, attachment style was not associated with serotonin transporter availability. Conclusions: Our results provide preliminary in vivo evidence that the opioid system may be involved in the neurocircuits associated with individual differences in adult attachment behavior. The results suggest that variation in $\mu$-opioid receptor availability may be linked with the individuals' social relationships and psychosocial well-being and thus contributes to risk for psychiatric morbidity.
\end{abstract}




\section{Introduction}

Mammals, including humans, are equipped with an innate bonding system that maintains infants' closeness to caretakers during threats and regulates support-seeking behavior (1). Such need to form and maintain close interpersonal relationships is fundamental to human life (2). Attachment style develops in a dynamic interaction between early interactive experiences with caregivers, environmental circumstances, and individuals' psychobiological qualities such as temperament (3). In childhood, attachment emerges as behavioral patterns in relation to primary caregivers. The attachment style can be divided into secure, avoidant and ambivalent attachment styles. Avoidant and ambivalent attachment can be further grouped together as insecure attachment style. Secure attachment is manifested in intrinsic reliance on others' good intentions and trust in others in distressing situations. Avoidant attachment describes a disposition to deny or hide one's negative emotions in threatening situations, to have excessive self-reliance, and to be unable to seek comfort from others. Finally, ambivalent attachment refers to one's uncertainty about others' support, leading to alertness across situations, fears of becoming rejected, and sensitivity to display negative emotions $(4,5)$. These attachment styles generalize to attachment-based strategies in romantic and other close relationships, and contribute to coping, emotion regulation and social behaviour in general (3). Further, the prototype of attachment style remains moderately stable from childhood to adulthood, although changes can occur by maturation and if encountering e.g. abuse, stressful life events, or severe conflicts in social relationships $(6,7)$.

Accumulating evidence also demonstrates that attachment style is important for mental health (8). For instance, insecure attachment is linked to a variety of psychiatric disorders, such as anxiety (9), depression (10), eating disorders (11) substance abuse (12), and psychosis (13), with some differences in the vulnerabilities between avoidant and ambivalent attachment styles. 
Accordingly, the World Health Organization has postulated that attachment should be one crucial target in early prevention of mental disorders. Attachment is also one of the NIMH's RDoC domains for research purposes (14). Hence, investigating the neurobiological basis of the attachment system could substantially advance our understanding about the etiological mechanisms of psychiatric disorders.

Neuropeptides oxytocin and vasopressin are involved in the formation of attachment relationships $(15,16)$, and recent studies have also elucidated the contribution of the dopamine system in social motivation $(17,18)$. However, the role of the serotonergic and opioid systems in human attachment has remained poorly understood. The role of endogenous opioids in modulating attachment was first suggested following the observation that exogenous opioid agonists alleviate separation distress of rat pups (19). Subsequently it has been argued that experiences of interpersonal warmth and social euphoria result in endogenous opioid release, and decline in endogenous opioid levels following social isolation drives the individual to search for interpersonal contacts (20). Previously, social touch is found to increase the $\mu$-opioid receptor availability (21). Animal studies have indeed suggested that social attachment is linked to $\mu$-opioid receptors in both prairie voles (22) and rhesus macaques (23). Further, genetic studies have found that attachment behavior is related to $\mu$-opioid receptor genes in rhesus monkeys (24) and in mice (25). In humans, opioid receptor density correlates with the frequency of prosocial behaviour such as social laughter (26), and one study has suggested that high avoidance in attachment correlates with lower $\mu$-opioid receptor availability in limbic emotion circuits and frontal cortex (27). Human studies on opioidergic basis of attachment have, however, relied on self-report questionnaires. Self-report questionnaires may cause bias for several reasons: questionnaires may cause anxiety and activate psychological defences, responses to questionnaires may be affected by current affective states and be less stable over long time periods, and the items are commonly summed together (without emphasizing some 
theoretically relevant issues over others) $(28,29)$. Therefore, additional work based on objective, interview-based external measurements of attachment behaviour are needed to elucidate how the endogenous opioid system contributes to human attachment style differences.

Childhood abuse, which is known to severely disrupt formation of secure attachment, is related to lower serotonin transporter availability in subjects with major depressive disorder (30). The serotonergic system is also linked with several subcomponents of attachment behaviour, such as social cognition and emotion regulation (31). Studies in rhesus monkeys have found that social subordination stress (32) and early maternal deprivation predict the level of serotonin transporter availability (33). Similarly, pharmacological studies in humans have suggested that modulation of the serotonin function change the appraisal of close relationships. For instance, both tryptophan depletion (34) and serotonin receptor blockade with citalopram (35) have been shown to result in lower ratings of relationship intimacy and quality. On the other hand, MDMA, leads to feelings of closeness with others and has been shown to enhance pleasantness of social touch (36) and increase prosocial behavior, possible via serotonergic mechanisms $(37,38)$. In summary, converging evidence suggests that the serotonin system and serotonin transporter in particular are an important molecular mechanism supporting close relationships. However, to our knowledge, no study has investigated directly whether human attachment style as such is related to the serotonin transporter availability.

In this study, we investigated whether attachment type is linked to functional alterations in opioid and serotonergic systems in vivo in the brain. We used positron emission tomography (PET) with radiotracers $\left[{ }^{11} \mathrm{C}\right]$ carfentanil and $\left[{ }^{11} \mathrm{C}\right]$ MADAM to measure $\mu$-opioid receptor and serotonin transporter availability, respectively. A sample of 39 volunteers with no current psychiatric disorders was recruited. Attachment styles were evaluated using the Adult Attachment Interview (AAI) (39) that was further analyzed with the Dynamic-Maturational Model of attachment and adaptation $(\mathrm{DMM}(4,5)$. Hence, attachment type assessment was 
based on reliable psychiatric interview that captures also unconscious representations about close interpersonal relationships. Based on previous indirect evidence, the starting hypotheses were that secure (vs. insecure) attachment would be associated with higher $\mu$-opioid receptor availability and higher serotonin transporter availability in brain regions associated with social emotional processing. We used both whole-brain approach and, as additional analysis, ROIbased approach (including amygdala, hippocampus, ventral striatum, dorsal caudate, thalamus, insula, orbitofrontal cortex, anterior cingulate cortex, middle cingulate cortex, and posterior cingulate cortex). 


\section{Methods and Materials}

This study is a part of a larger 'Neurobiology of Personality' project at the University of Turku and University of Helsinki, Finland and a substudy of a population-based, still on-going nationwide prospective cohort study "The Cardiovascular Risk in Young Finns Study" (YFS) that started in 1980 with pre-existing somatic health and psychological data. Participants (Table 1) were selected from the YFS sample on the basis of their Harm Avoidance (HA) scores (a scale of the Temperament and Character Inventory). The recruited subject groups with high vs. low HA were matched with regard to age, gender, and educational level. We invited all the participants with low/high HA who could be matched with each other with regard to age, gender, and educational level. Two such subsamples (with high and low HA) were collected: in the first sample past or present psychiatric disorders were excluded $(n=22)(40)$; and in the second sample subjects (not published before) were allowed to have past but not current psychiatric disorders making the whole study group less selected. A more detailed description of the recruitment is available elsewhere $(40,41,42)$.

The current study protocol was approved by the Joint Ethical Committee of the University of Turku and the Turku University Central Hospital. After the nature of the procedures had been fully explained in written from, all the participants gave written consent that was approved by the Ethical Committee. The study was conducted in accordance with the ethical guidelines of the Declaration of Helsinki.

All participants were healthy as confirmed by medical examination and interview, blood and urine screening, ECG, MRI examination. Regular smoking was an exclusion criterium because smoking influences the binding potential for $\left[{ }^{11} \mathrm{C}\right]$ carfentanil. SCID-I interview (Structured Clinical Interview for DSM-IV) was used to exclude any current DSM IV-axis I 
diagnosis. Depressive symptoms were also assessed using the Hamilton Depression Rating Scale (HAM-D-17) (all subjects had scores <10). None of the subjects had current psychiatric medication. In order to increase the representativeness of the sample, previous mild/moderate depressive episodes or mild/moderate anxiety symptomatology (in 6 subjects) were not regarded as exclusion criteria. All the subjects were ethnic Finns. There was no difference in Harm Avoidance between subjects with secure vs. insecure attachment $(\mathrm{p}=0.14)$.

\section{TABLE 1 ABOUT HERE}

\subsection{Attachment style measurement}

Attachment style was determined by conducting the AAI (39) that was then coded with the DMM coding scheme $(4,5)$. The AAI interview exposes the subject to memories of threats to important attachments and is a procedure for assessing adults' strategies for identifying, preventing, and protecting the self from perceived dangers, particularly dangers tied to intimate relationships. It investigates how the subject is able to recall and narrate the events, persons and feelings linked to the threat. The AAI is thus used as a tool to stimulate the attachment strategies which can then be analyzed according to the DMM model. For more information, please see Supplementary Material 1. The DMM has been widely used also previously $(43,44,45)$. The DMM coding has good construct validity (44) and has been validated in samples with various psychiatric disorders such as personality disorders, depression, and PTSD (46, 47, 48, 49).

In this study, AAI was conducted shortly after the PET session within the same day. Subjects were classified as having secure $(\mathrm{N}=16)$, avoidant $(\mathrm{N}=14)$ and ambivalent $(\mathrm{N}=9)$ attachment types. Classifications were made by an experienced AAI interpreter (A.H.) with training qualifications on DMM and AAI. Due to a limited sample size, our primary analysis was focused on the comparison between the securely versus insecurely (avoidantly or 
ambivalently) attached subjects, even though full three-category attachment style classification was used and corresponding three-class analyses were also run. The grouping of avoidant and ambivalent attachment styles of the DMM has been utilized in previous reports but is clearly not the ideal solution (44). Independent samples t-test showed that different attachment type groups did not differ significantly with regard to age. However, chi square test showed that men were more likely to have insecure (avoidant or ambivalent) attachment and women were more likely to have secure attachment $(p<0.05)$. There were no differences between securely vs. insecurely attached subjects in age, parents' educational level, subjects' educational level in adulthood, or number of stressful life events in childhood.

\subsection{PET imaging}

A brain-dedicated high-resolution PET scanner (ECAT HRRT, Siemens Medical Solutions) was used for PET imaging. Prior to emission scan, Cesium-137 point source transmission was used to obtain tissue attenuation maps by forward projection. These maps were then used for attenuation correction. Data was gathered in list mode and reconstructed into $1.22 \times 1.22 \times 1.22$ mm3 voxel size images with speed-optimized Ordinary Poisson-OSEM in full 3D reconstruction (50). During the PET scans, head of the subject was fixed using an individually molded thermoplastic mask. A T1-weighted MRI scan with $1 \times 1 \times 1 \mathrm{~mm} 3$ resolution voxel size was obtained from each subject using Philips Gyroscan Intera 1.5 T CV Nova Dual MRI scanner to exclude structural abnormalities and for anatomical reference.

All subjects underwent a PET scan with serotonin transporter tracer $\left[{ }^{11} \mathrm{C}\right] \mathrm{MADAM}$ followed by a PET scan with $\mu$-opioid receptor tracer $\left[{ }^{11} \mathrm{C}\right]$ carfentanil during the same day using identical head positioning as described in (41) (Figure 1). Radiochemistry procedures of the tracers has been described in detail elsewhere $(40,41)$. Tracers were injected as intravenous bolus injections and flushed with saline. The injected doses and masses were $484.5 \pm 49.9 \mathrm{MBq}$ 
and $0.59 \pm 0.42 \mu \mathrm{g}$ for $\left[{ }^{11} \mathrm{C}\right] \mathrm{MADAM}(\mathrm{n}=37)$ and $423.6 \pm 73.9 \mathrm{MBq}$ and $1.08 \pm 0.84 \mu \mathrm{g}$ for $\left[{ }^{11} \mathrm{C}\right]$ carfentanil $(\mathrm{n}=39)$, respectively. Radioactivity of $\left[{ }^{11} \mathrm{C}\right]$ MADAM was measured for $75 \mathrm{~min}$ using 17 frames $(3 \times 1 \mathrm{~min}, 4 \times 3 \mathrm{~min}$, and $10 \times 6 \mathrm{~min})$ and radioactivity of $\left[{ }^{11} \mathrm{C}\right]$ carfentanil for 69 min using 16 frames $(3 \times 1 \mathrm{~min}, 4 \times 3 \mathrm{~min}$, and $9 \times 6 \mathrm{~min})$.

\section{FIGURE 1 ABOUT HERE}

\subsection{PET image processing}

PET images were preprocessed using the automated PET data processing pipeline Magia (51) (https://github.com/tkkarjal/magia) running on MATLAB (The MathWorks, Inc., Natick, Massachusetts, United States). PET data was first corrected for motion by realigning the frames of each scan. Radiotracer binding was quantified using nondisplaceable binding potential $\left(B P_{\mathrm{ND}}\right)$, which is the ratio of specific binding to non-displaceable binding in the tissue $(52)$. This outcome measure is not confounded by differences in peripheral distribution or radiotracer metabolism. The $\mathrm{BP}_{\mathrm{ND}}$ is taken here as an estimate for number of target receptor/transporter available for tracer binding (receptor availability). Binding potential was calculated applying basis function method for each voxel using the simplified reference tissue model (53), with occipital cortex $\left(\left[{ }^{11} \mathrm{C}\right]\right.$ carfentanil) or cerebellar gray matter $\left(\left[{ }^{11} \mathrm{C}\right] \mathrm{MADAM}\right)$ serving as the reference regions. The parametric images were spatially normalized to MNI-space via segmentation and normalization of T1-weighted anatomical images, and finally smoothed with an 8-mm full-width half maximum Gaussian kernel.

\subsection{Statistical analysis}

The population-level full volume statistical analysis was done using SPM12. The normalized and smoothed $B P_{\mathrm{ND}}$ images were entered into general linear model, where $B P_{\mathrm{ND}}$ was predicted 
with attachment style (using a three-class variable of attachment styles and also a two-class variable by collapsing subjects into securely vs. insecurely attached), separately for $\mu-$ opioid receptor and serotonin transporter. Statistical threshold was set at $\mathrm{p}<0.025$, FDR-corrected at cluster level. In a complementary methodological approach, the data were analyzed by averaging $B P_{\mathrm{ND}}$ 's within regions of interest (ROIs). Atlas-based ROIs were generated in the $\mu-$ opioid receptor -rich regions in the brain (amygdala, hippocampus, ventral striatum, dorsal caudate, thalamus, insula, orbitofrontal cortex (OFC), anterior cingulate cortex (ACC), middle cingulate cortex (MCC), and posterior cingulate cortex (PCC) using AAL (54) and Anatomy (55) toolboxes. Mean regional $\left[{ }^{11} \mathrm{C}\right]$ carfentanil and $\left[{ }^{11} \mathrm{C}\right] \mathrm{MADAM} B P_{\mathrm{ND}}$ were extracted for each region. Data were analysed with $\mathrm{R}$ statistical software (https://cran.r-project.org) using analysis of variance. Since age may affect $\left[{ }^{11} \mathrm{C}\right]$ carfentanil and $\left[{ }^{11} \mathrm{C}\right] \mathrm{MADAM} B P_{\mathrm{ND}}$, analysis were run separately with and without age as a covariate. In addition, since attachment was affected by sex in this sample, we ran additional analyses with sex as a covariate. 


\section{Results}

First, we compared the $\mu-$ opioid receptor availability and serotonin transporter availability between securely and insecurely attached subjects in a voxel-wise manner. This analysis revealed that $\mu$-opioid receptor availability was significantly higher in the securely attached subjects bilaterally in the amygdala, hippocampus, thalamus, and also in the right lateral prefrontal cortex (Figure 2) (thresholded at $p<.025$, FDR corrected). Three way-ANOVA in SPM between all the attachment style groups yielded corroborating findings, revealing significant differences in the amygdala-hippocampal complex. No statistically significant effects were observed for serotonin transporter availability between subjects with different attachment styles.

Secondly, we investigated whether there are differences in $\mu$-opioid receptor availability and serotonin transporter availability in the ROIs that are previously found to associate with socioemotional processing (i.e. amygdala, hippocampus, ventral striatum, dorsal caudate, thalamus, insula, orbitofrontal cortex, anterior cingulate cortex, middle cingulate cortex, and posterior cingulate cortex). The ROI analysis mainly confirmed the results of the full-volume analysis (Table 2 and Figure 3). Specifically, subjects with secure attachment had higher binding potential for $\left[{ }^{11} \mathrm{C}\right]$ carfentanil in the hippocampus $(p=0.001)$, amygdala ( $p=0.010$ ), and thalamus ( $p=0.042)$ but not in the other ROIs, when compared to participants with insecure attachment. Further, we obtained no differences in $\left[{ }^{11} \mathrm{C}\right]$ MADAM between securely and insecurely attached subjects in any of the ROIs. These findings were obtained without covariates. All the associations remained significant after adjusting for age: subjects with secure attachment had higher binding potential for $\left[{ }^{11} \mathrm{C}\right]$ carfentanil in the hippocampus ( $p=0.001)$, amygdala $(p=0.012)$, and thalamus $(p=0.046)$ but not in the other ROIs, when compared to participants with insecure attachment. 
In addition, an exploratory analysis with both age and sex as covariates confirmed a significant secure attachment-opiate receptor association in the hippocampus but not in the other ROIs (Supplementary Figure 1). Due to the comparatively small cell sizes and categorical outcome variable, we did not run the analyses separately among males and females.

As a complementary analysis, we also investigated the differences in binding potentials for $\left[{ }^{11} \mathrm{C}\right]$ carfentanil and $\left[{ }^{11} \mathrm{C}\right] \mathrm{MADAM}$ in the ROIs between participants with a 3-class variable of attachment type (secure, anxious, or ambivalent). The variance analyses showed that there were group differences in $\left[{ }^{11} \mathrm{C}\right]$ carfentanil $B P_{\mathrm{ND}}$ in hippocampus and amygdala but not in the other ROIs. Post hoc tests (Tukey's tests) showed that participants with anxious attachment had lower $\left[{ }^{11} \mathrm{C}\right]$ carfentanil $B P_{\mathrm{ND}}$ in hippocampus $(p<0.001)$ and amygdala $(p=0.004)$, when compared to participants with secure attachment. Post hoc tests showed no other between-group differences in $\left[{ }^{11} \mathrm{C}\right]$ carfentanil $B P_{\mathrm{ND}}$ (i.e. no differences between avoidant vs. secure attachment or between avoidant vs. anxious attachment).

\section{FIGURES 2 AND 3 ABOUT HERE}

TABLE 2 ABOUT HERE

\section{Discussion}

Our findings suggest that secure attachment is associated with higher $\mu$-opioid receptor availability in the hippocampus, amygdala, thalamus and prefrontal cortex, whereas the attachment style is not associated with serotonin transporter availability in analyses using age as a covariate. The association of secure attachment with higher $\mu-$ opioid receptor availability in the hippocampus remained significant also after adding sex as a covariate in the model as sex unexpectedly associated with attachment style. Although literature on sex differences in $\mu-$ 
opioid receptor availability is not consistent (see Kantonen et al., 2020), we cannot fully exclude the effect of sex or hormonal factors on the association between attachment and $\mu$-opioid receptor availability in the hippocampus/amygdala-thalamus-prefrontal cortex circuitry. The attachment type was evaluated with a structured objective psychiatric interview evaluated by a trained rater $(4,5)$. This method captures also less consciously accessible representations about relationships with close others and is a more comprehensive way of describing adult attachment styles that is not synonymous with the early childhood attachment. Rather, childhood attachment patterns continue to function as a working model for relationships in adulthood. The presently observed results are in line with prior PET studies indicating a crucial role of the $\mu-$ opioid system for attachment and sociability in humans $(26,27,56,60,61)$, and suggest that there are similar parallels in opioid basis of the attachment system across primates and other mammals $(1,20)$.

High $\mu$-opioid receptor availability measured with binding potential for $\left[{ }^{11} \mathrm{C}\right]$-carfentanil can be interpreted as increased density of the MOR agonist sites available for tracer binding. However, there is evidence that binding potential for $\left[{ }^{11} \mathrm{C}\right]$-carfentanil can be modulated by synaptic concentrations of endogenous opioids (such as $\beta$-endorphin or encephalins) via direct binding competition or potentially via long-term changes in endogenous opioid concentrations causing compensatory changes in receptor binding dynamics (such as receptor internalization) (57-59). Thus, the link between higher binding potential for $\left[{ }^{11} \mathrm{C}\right]$ carfentanil and secure attachment could be explained by either increased receptor availability or altered endogenous opioid release, or a combination of both. Specific pharmacological challenge studies using the $\left[{ }^{11} \mathrm{C}\right]$-carfentanil binding paradigm would be needed to distinguish between these mechanisms.

\subsection{The opioid system and neurocircuits related to human attachment}


In this study, the participants were not exposed to any attachment-related stimuli during PET imaging. Hence, this study investigated the stable differences in the endogenous opioid system. Our results together with other results (27) indicate that secure attachment is related to higher mu-opioid receptor availability. Previous studies, in turn, indicate that exposure to social rejection and acceptance are both related to increased endogenous opioid release (i.e. lower muopioid receptor availability) in some brain regions $(56,60)$. Interestingly, increased endogenous opioid release correlates with decreased negative affect during rejection and greater social motivation during acceptance $(56,60)$. Hence, increased endogenous opioid release appears to make an individual more sensitive to changes (whether positive or negative) in social interaction. Future studies could investigate whether secure vs. insecure attachment is related to different reactivity of the endogenous opioid system in response to changes in social situations (e.g. acceptance or rejection).

Most prominent attachment style dependent variations in $\mu$-opioid receptor availability were observed in amygdala and hippocampus, regions which have high $\mu$-opioid receptor density and which also contribute centrally to human socioemotional functions $(62,63)$. These results are consistent with those observed previous molecular imaging studies using questionnaire-based measures of adult romantic attachment, suggesting concordance between brain basis for romantic and other types of attachment (27). Our findings are also consistent with genetic studies on the linkage between $\mu$-opioid receptor and attachment behavior in animals. $\mu$-opioid receptor knock-out mice also express deficient maternal attachment (25) and conversely monkey infants with gain-of-function OPRM1 77G allele display enhanced maternal attachment (24).

The present results suggest that insecure attachment is related to changes in opioid transmission in wide brain networks responsible for socioemotional processing, ranging from primary emotional appraisal to more sophisticated socio-cognitive processing. Previously, it 
has been shown that the activity level and grey matter volume of amygdala and hippocampus are related to social appraisal (64), processing of attachment-related social stimuli (65) and experiencing separation anxiety (66). Temporal regions, in turn, are involved in face recognition and theory of mind processing (67). Further, frontal regions are related to social control and emotional decision-making (68). Functional imaging studies have also found that that individuals with anxious attachment respond to thoughts of loss with increased activity of emotion-related brain areas (e.g. anterior temporal lobe) and reduced activity of the frontal regions responsible for emotion regulation (69). Moreover, insecure attachment styles are related to altered activity patterns in amygdala and striatum in response to facial expressions of emotions, indicating neurobiological changes in sensitivity to social reward and social punishment (64). Thus, attachment styles might be related to differences in the evaluation of safety versus threat in social interactions and that this process takes place in a brain network including regions such as amygdala, hippocampus, and medial prefrontal cortex (70). It is possible that the opioid system might also contribute to the management of both actual and anticipated safety and threat related episodes in social relationships. This is because the opioid system acts as a buffer against psychological stressors $(61,71)$ and because the OPRM1 gene is found to influence the self-experienced security during romantic partner's quarrelsome behavior (72). This view is supported by pharmacological studies in primates, which have found that opioid antagonist administration increases social grooming in monkeys $(73,74)$, whereas opioid agonists alleviate separation distress in pups (19). Finally, pharmacological studies in humans have shown that naltrexone alters the response of the ventral striatum when exposed to images of close others and also reduces feelings of social connection to the close others (75, 76).

The brain opioid theory of social attachment proposes that feelings of interpersonal warmth and social euphoria are related to endogenous opioid release and, conversely, social 
isolation results in a lower level of endogenous opioids (20). Our data show that secure attachment is related to a higher $\mu$-opioid receptor availability when compared to avoidant or ambivalent attachment. In numerous psychiatric disorders, the core symptomatology refers to disturbances in social interaction, especially in threatening or distressing situations. For example, patients with major depressive disorder exhibit altered endogenous opioide release in response to others' rejection and acceptance (46). Typically, the disturbances in social interaction derive from early experience with attachment figures. For example, major depressive disorder typically includes experiencing shame and worthlessness in relation to others; anxiety disorders contain hostile interpretation biases of others' behavior; paranoid disorder refers to beliefs about others' vicious intentions towards the self; and schizophrenia commonly includes a strong tendency to social isolation. Against this background, our findings may provide new neurobiological insights as to why individuals with psychopathologies may experience social contacts as less rewarding, or even threatening and hostile and why their socio-cognitive processing may be more biased towards negative affect.

The opioid system, however, works in tandem with numerous other neurotransmitter systems when governing social behavior. It has been suggested that opioids help to maintain secure relationships in adulthood by making social contacts more rewarding, whereas oxytocin and vasopressin may increase parental nurturing and facilitate the formation of secure parentchild relationship (15) (16). It has been found that the opioid system is involved in the regulation of oxytocin secretion, so that opioid release has an inhibitory influence on oxytocin release, possibly inhibiting nurturing behavior (77). Hence, it is possible that the opioid system modulates parent-child attachment, yet this hypothesis currently lacks direct empirical support.

In contrast to the opioid system, the associations between attachment style and the serotonin transporter in this sample of healthy subjects were not statistically significant. Converging lines of evidence have suggested that the serotonin system could be related to 
attachment styles. For instance, disturbed attachment style may convey the risk for depression (9), which suggests that that similar serotonergic abnormalities could be seen in depression and insecure attachment. Especially because other known risk factors for depression, such as personality trait neuroticism, has been associated with altered serotonin transporter density (78). Although there is high variability between individual studies (79), a meta-analysis suggests lower serotonin transporter density in major depression (80). Therefore, we expected to find a lower serotonin system function in people who have insecure attachment but we did not find evidence for this hypothesis. It is feasible that neuroticism is mainly an indicator of a higher genetic predisposition to depression, whereas attachment style may be influenced more by the environment. Finally, serotonin transporter is only one component in the serotonin system and other components of the serotonin system such as serotonin receptor subtype expression may explain variability in the attachment style.

\subsection{Limitations}

Firstly, although the sample size in this study $(\mathrm{N}=39)$ was relatively large for a PET investigation, it includes a limited amount of statistical power and increases risk for false negative or false positive findings. The serotonin transporter availability (the binding potential for $\left.\left[{ }^{11} \mathrm{C}\right] \mathrm{MADAM}\right)$ in the secure attachment group was $12 \%$ higher in the hippocampus and 8 $\%$ higher in the amygdala than in the insecure attachment group. These associations, however, were not statistically significant, and it was not possible to completely rule out a false negative finding. Secondly, due to the small cell sizes, we combined the participants with avoidant or ambivalent attachment into one study group. Optimally, avoidant and anxious attachment style should be investigated separately since they may be differently related to some aspects of neurotransmitter systems. Thirdly, due to our small sample size, it was not reasonable to run analyses separately among males and females. Hence, we cannot fully exclude the possibility 
that sex differences or hormonal effects may partly explain the association between attachment and $\mu$-opioid receptor availability. Finally, there were 6 participants with past but not current affective psychiatric disorders in our sample. However, since the serotonin transporter availability does not differ between patients who have recovered from major depressive disorder and individuals who have never been depressed (80), it is unlikely that including these participants would explain the lack of associations between the serotonin transporter and attachment style.

\section{Conclusions}

This study showed that the secure attachment is related to higher $\mu$-opioid receptor availability in amygdala and hippocampus when compared to avoidant or ambivalent attachment. However, there was no link between attachment style and serotonin transporter availability. Our findings provide new insights into the neurobiological mechanisms between disturbances in attachment and related psychiatric morbidity.

\section{Conflict of interest}

J.H. received lecture fees from Orion Corp and H. Lundbeck Ab. The other authors report no biomedical financial interests or potential conflict of interest.

\section{Acknowledgements}

This study was financially supported by the Academy of Finland (grant \#116321 to J.H., grant \#304385 to L.N.), the Gyllenberg Foundation (A.S.), and Turku University Hospital (EVO grants, P3848).

\section{Author contributions}


J.H., L.K.-J., and O.R. designed the study, recruited the subjects, and wrote the manuscript. L.T. recruited the study subjects, collected the data, analyzed the data, and wrote the manuscript. L.N., A.S., and R.-L.A. analyzed the data and wrote the manuscript. O.T. contributed to the clinical evaluations and wrote the manuscript. M.T., A.H., and H.L. wrote the manuscript.

\section{References}

1. Nelson EE, Panksepp J: Brain Substrates of Infant-Mother Attachment: Contributions of Opioids, Oxytocin, and Norepinephrine. Neurosci Biobehav Rev 1998; 22:437-452

2. Bowlby J: Attachment and loss: Attachment. 2nd ed. New York, 1982

3. Mikulincer M, Shaver PR: Attachment in adulthood: Structure, dynamics, and change. Guilford Press, 2007

4. Crittenden P: Attachment in adulthood: coding manual for the dynamic-maturational approach to the Adult Attachment Interview. Unpubl Manuscr Miami FL 1999;

5. Crittenden PM, Landini A: Assessing adult attachment: A dynamic-maturational approach to discourse analysis. WW Norton \& Company, 2011

6. Fraley CR: Attachment stability from infancy to adulthood: Meta-analysis and dynamic modeling of developmental mechanisms. Pers Soc Psychol Rev 2002; 6: 123 151.

7. Waters E, Merrick S, Treboux D, Crowell, J., Albersheim, L. (2003). Attachment Security in Infancy and Early Adulthood: A Twenty-Year Longitudinal Study. Child Dev 2000; 71:684-689

8. Mikulincer M, Shaver PR: An attachment perspective on psychopathology. World Psychiatry 2012; 11:11-15 
9. Esbjørn BH, Bender PK, Reinholdt-Dunne ML, Munck LA, Ollendick TH: The Development of Anxiety Disorders: Considering the Contributions of Attachment and Emotion Regulation. Clin Child Fam Psychol Rev 2012; 15:129-143

10. Sloman L, Gilbert P, Hasey G: Evolved mechanisms in depression: the role and interaction of attachment and social rank in depression. J Affect Disord 2003; 74:107121

11. Zachrisson HD, Skårderud F: Feelings of insecurity: Review of attachment and eating disorders. Eur Eat Disord Rev 2010; 18:97-106

12. Kassel JD, Wardle M, Roberts JE: Adult attachment security and college student substance use. Addict Behav 2007; 32:1164-1176

13. Berry K, Barrowclough C, Wearden A: A review of the role of adult attachment style in psychosis: unexplored issues and questions for further research. Clin Psychol Rev $2007 ; 27: 458-475$

14. Cuthbert BN: The RDoC framework: facilitating transition from ICD/DSM to dimensional approaches that integrate neuroscience and psychopathology. World Psychiatry $2014 ; 13: 28-35$

15. Young AM: Increased extracellular dopamine in nucleus accumbens in response to unconditioned and conditioned aversive stimuli: studies using 1 min microdialysis in rats. J Neurosci Methods 2004; 138:57-63

16. Johnson ZV, Young LJ: Neurobiological mechanisms of social attachment and pair bonding. Curr Opin Behav Sci 2015; 3:38-44

17. Caravaggio F, Fervaha G, Chung JK, Gerretsen P, Nakajima S, Plitman E et al.: Exploring personality traits related to dopamine D2/3 receptor availability in striatal subregions of humans. Eur Neuropsychopharmacol 2016; 26:644-652 
18. Atzil S, Touroutoglou A, Rudy T, Salcedo S, Feldman R, Hooker JM, et al.: Dopamine in the medial amygdala network mediates human bonding. Proc Natl Acad Sci $2017 ; 114: 2361$

19. Panksepp J, Herman B, Conner R, Bishop P, Scott JP: The biology of social attachments: opiates alleviate separation distress. Biol Psychiatry 1978;

20. Machin AJ, Dunbar RI: The brain opioid theory of social attachment: a review of the evidence. Behaviour 2011; 148:985-1025

21. Nummenmaa, L., Tuominen, L., Dunbar, R., Hirvonen, J., Manninen, S., Arponen, E., et al.: Social touch modulates endogenous $\mu$-opioid system activity in humans. NeuroImage 2016; 138:242-247.

22. Burkett JP, Spiegel LL, Inoue K, Murphy AZ, Young LJ: Activation of $\mu$-Opioid Receptors in the Dorsal Striatum is Necessary for Adult Social Attachment in Monogamous Prairie Voles. Neuropsychopharmacology 2011; 36:2200-2210

23. Graves FC, Wallen K, Maestripieri D: Opioids and attachment in rhesus macaque (Macaca mulatta) abusive mothers. Behav Neurosci 2002; 116:489-493

24. Barr CS, Schwandt ML, Lindell SG, Higley JD, Maestripieri D, Goldman D, et al.: Variation at the mu-opioid receptor gene (OPRM1) influences attachment behavior in infant primates. Proc Natl Acad Sci 2008; 105:5277-5281

25. Moles A, Kieffer BL, D'Amato FR: Deficit in Attachment Behavior in Mice Lacking the $\mu$-Opioid Receptor Gene. Science 2004; 304:1983

26. Manninen S, Tuominen L, Dunbar RI, Karjalainen T, Hirvonen J, Arponen E, et al.: Social laughter triggers endogenous opioid release in humans. J Neurosci 2017; 37:6125-6131 
27. Nummenmaa L, Manninen S, Tuominen L, Hirvonen J, Kalliokoski KK, Nuutila P, et al.: Adult attachment style is associated with cerebral $\mu$-opioid receptor availability in humans. Hum Brain Mapp 2015; 36:3621-3628

28. Fraley RC, Waller NG, Brennan KA: An item response theory analysis of self-report measures of adult attachment. J Pers Soc Psychol 2000; 78:350-365.

29. Jacobvitz D, Curran M, Moller N : Measurement of adult attachment: The place of self-report and interview methodologies. Attach Hum Dev 2002; 4:207-215.

30. Miller JM, Kinnally EL, Ogden RT, Kinnally EL, Ogden RT, Mann JJ, Parsey RV: Reported childhood abuse is associated with low serotonin transporter binding in vivo in major depressive disorder. Synapse 2009; 63:565-573

31. Canli T, Lesch K-P: Long story short: the serotonin transporter in emotion regulation and social cognition. Nat Neurosci 2007; 10:1103-1109

32. Embree M, Michopoulos V, Votaw JR, Voll RJ, Mun J, Stehouwer JS, et al.: The relation of developmental changes in brain serotonin transporter (5HTT) and 5HT1A receptor binding to emotional behavior in female rhesus monkeys: Effects of social status and 5HTT genotype. Neuroscience 2013; 228:83-100

33. Ichise M, Vines DC, Gura T, Anderson GM, Suomi SJ, Higley JD, et al.: Effects of early life stress on [11C]DASB positron emission tomography imaging of serotonin transporters in adolescent peer- and mother-reared rhesus monkeys. J Neurosci 2006; $26: 4638-43$

34. Bilderbeck AC, McCabe C, Wakeley J, McGlone F, Harris T, Cowen PJ, et al.: Serotonergic Activity Influences the Cognitive Appraisal of Close Intimate Relationships in Healthy Adults. Biol Psychiatry 2011; 69:720-725 
35. Bilderbeck AC, Wakeley J, Godlewska BR, McGlone F, Harris T, Cowen PJ, et al.: Preliminary evidence that sub-chronic citalopram triggers the re-evaluation of value in intimate partnerships. Soc Cogn Affect Neurosci 2014; 9:1419-1425

36. Bershad AK, Mayo LM, Van Hedger K, McGlone F, Walker SC, de Wit H: Effects of MDMA on attention to positive social cues and pleasantness of affective touch. Neuropsychopharmacology 2019; 44:1698-1705

37. Preller KH, Pokorny T, Hock A, Kraehenmann R, Stämpfli P, Seifritz E, et al.: Effects of serotonin 2A/1A receptor stimulation on social exclusion processing. Proc Natl Acad Sci 2016; 113:5119-5124

38. Morley KC, Arnold JC, McGregor IS: Serotonin (1A) receptor involvement in acute 3, 4-methylenedioxymethamphetamine (MDMA) facilitation of social interaction in the rat. Prog Neuropsychopharmacol Biol Psychiatry 2005; 29:648-657

39. George C, Kaplan N, Main M: Adult attachment interview1996;

40. Tuominen L, Salo J, Hirvonen J, Någren K, Laine P: Temperament, character and serotonin activity in the human brain: a positron emission tomography study based on a general population cohort. Psychol Med 2012; 1-14

41. Tuominen L, Salo J, Hirvonen J, Någren K, Laine P, Melartin T, et al.: Temperament trait Harm Avoidance associates with $\mu$-opioid receptor availability in frontal cortex: a PET study using [(11)C]carfentanil. Neuroimage 2012; 61:670-6

42. Raitakari OT, Juonala M, Rönnemaa T, Keltikangas-Järvinen L, Räsänen L, Pietikäinen M, et al.: Cohort profile: the cardiovascular risk in Young Finns Study. Int J Epidemiol 2008; 37:1220-6

43. Hautamäki A, Hautamäki L, Neuvonen L, Maliniemi-Piispanen S: Transmission of attachment across three generations. Eur J Dev Psychol 2010; 7:618-634. 
44. Pace AL, Bufford RK: Assessing Adult Attachment: Relation and Validity of two Dynamic-Maturational Model Approaches. Interpers Int J Pers Relatsh 2018; 12:232253.

45. Shah PE, Fonagy P, Strathearn L: Is attachment transmitted across generations? The plot thickens. Clin Child Psychol Psychiatry 2010; 15:329-345.

46. Crittenden PM, Newman L: Comparing models of borderline personality disorder: mothers' experience, self-protective strategies, and dispositional representations. Clin Child Psychol Psychiatry 2010; 15:433-451.

47. Gullestad SE: The Adult Attachment Interview and psychoanalytic outcome studies. Int J Psychoanal 2003; 84:651-668.

48. Crittenden PM, Heller MB: The roots of chronic posttraumatic stress disorder: Childhood trauma, information processing, and self-protective strategies. Chronic Stress 2017; 1:2470547016682965.

49. Farnfield S, Hautamäki A, Nørbech P, Sahhar N: DMM assessments of attachment and adaptation: Procedures, validity and utility. Clin Child Psychol Psychiatry 2010; $15: 313-328$

50. Comtat C, Bataille F, Michel C, Jones JP, Sibomana M, Janeiro L, et al.: OSEM-3D reconstruction strategies for the ECAT HRRT. 2004 IEEE Nucl Sci Symp Conf Rec Vols 1-7 2004; 3492-3496

51. Karjalainen T, Tuisku J, Santavirta S, Kantonen T, Tuominen L, Hirvonen J, et al.: Magia: Robust Automated Image Processing and Kinetic Modeling Toolbox for PET Neuroinformatics. Front Neuroinformatics 2020; 14:3-3

52. Innis RB, Cunningham VJ, Delforge J, Fujita M, Gjedde A, Gunn RN, et al.: Consensus nomenclature for in vivo imaging of reversibly binding radioligands. $\mathrm{J}$ Cereb Blood Flow Metab 2007; 27:1533-9 
53. Gunn RN, Lammertsma AA, Hume SP, Cunningham VJ: Parametric imaging of ligand-receptor binding in PET using a simplified reference region model. Neuroimage 1997; 6:279-87

54. Tzourio-Mazoyer N, Landeau B, Papathanassiou D, Crivello F, Etard O, Delcroix N, et al.: Automated anatomical labeling of activations in SPM using a macroscopic anatomical parcellation of the MNI MRI single-subject brain. Neuroimage 2002; $15: 273-89$

55. Eickhoff SB, Stephan KE, Mohlberg H, Grefkes C, Fink GR, Amunts K: A new SPM toolbox for combining probabilistic cytoarchitectonic maps and functional imaging data. NeuroImage 2005; 25:1325-1335

56. Hsu DT, Sanford BJ, Meyers KK, Love TM, Hazlett KE, Walker SJ, et al.: It still hurts: altered endogenous opioid activity in the brain during social rejection and acceptance in major depressive disorder. Mol Psychiatry 2015; 20:193-200

57. Ghitza UE: Human brain imaging of opioid receptors: application to CNS biomarker and drug development. In Imaging of the Human Brain in Health and Disease (pp. 8198). Academic Press, 2014.

58. Quelch DR, Katsouri L, Nutt DJ, Parker CA, Tyacke RJ: Imaging endogenous opioid peptide release with [11C] carfentanil and [3H] diprenorphine: influence of agonistinduced internalization. J Cereb Blood Flow Metab 2014; 34:1604-1612.

59. Stohler CS, Zubieta JK: Pain imaging in the emerging era of molecular medicine. In Analgesia (pp. 517-537). Humana Press, Totowa, NJ, 2010.

60. Hsu DT, Sanford BJ, Meyers KK, Love TM, Hazlett KE, Wang H, et al.: Response of the $\mu$-opioid system to social rejection and acceptance. Mol Psychiatry 2013; $18: 1211-7$ 
61. Karjalainen T, Karlsson HK, Lahnakoski JM, Glerean E, Nuutila P, Jääskeläinen IP, et al.: Dissociable Roles of Cerebral $\mu$-Opioid and Type 2 Dopamine Receptors in Vicarious Pain: A Combined PET-fMRI Study. Cereb Cortex 2017; 27:4257-4266

62. Zald DH: The human amygdala and the emotional evaluation of sensory stimuli. Brain Res Rev 2003; 41:88-123

63. Nummenmaa L, Tuominen L: Opioid system and human emotions. Br J Pharmacol $2018 ; 175: 2737-2749$

64. Vrticka P, Andersson F, Grandjean D, Sander D, Vuilleumier P: Individual attachment style modulates human amygdala and striatum activation during social appraisal. PloS One 2008; 3:e2868-e2868

65. Riem MME, Bakermans-Kranenburg MJ, van IJzendoorn MH, Out D, Rombouts SARB: Attachment in the brain: adult attachment representations predict amygdala and behavioral responses to infant crying. Attach Hum Dev 2012; 14:533-551

66. Redlich R, Grotegerd D, Opel N, Kaufmann C, Zwitserlood P, Kugel H, et al.: Are you gonna leave me? Separation anxiety is associated with increased amygdala responsiveness and volume. Soc Cogn Affect Neurosci 2014; 10:278-284

67. Lahnakoski JM, Glerean E, Salmi J, Jääskeläinen IP, Sams M, Hari R, et al.: Naturalistic FMRI mapping reveals superior temporal sulcus as the hub for the distributed brain network for social perception. Front Hum Neurosci 2012; 6:233

68. Amodio DM, Frith CD: Meeting of minds: the medial frontal cortex and social cognition. Nat Rev Neurosci 2006; 7:268-277

69. Gillath O, Bunge SA, Shaver PR, Wendelken C, Mikulincer M: Attachment-style differences in the ability to suppress negative thoughts: Exploring the neural correlates. Spec Sect Soc Cogn Neurosci 2005; 28:835-847 
70. Vrticka P, Vuilleumier P: Neuroscience of human social interactions and adult attachment style. Front Hum Neurosci 2012; 6:212

71. Karjalainen T, Seppälä K, Glerean E, Karlsson HK, Lahnakoski JM, Nuutila P, et al.: Opioidergic regulation of emotional arousal: A combined PET-fMRI study. Cereb Cortex 2019; 29:4006-4016

72. Tchalova K, Sadikaj G, Moskowitz DS, Zuroff DC, Bartz JA: Variation in the $\mu-$ opioid receptor gene (OPRM1) and experiences of felt security in response to a romantic partner's quarrelsome behavior. Molecular Psychiatry 2019; 29:4006-4016.

73. Keverne EB, Martensz ND, Tuite B: Beta-endorphin concentrations in cerebrospinal fluid of monkeys are influenced by grooming relationships.

Psychoneuroendocrinology 1989; 14:155-161

74. Fabre-Nys C, Meller RE, Keverne E: Opiate antagonists stimulate affiliative behaviour in monkeys. Pharmacol Biochem Behav 1982; 16:653-659

75. Inagaki TK, Hazlett LI, Andreescu C: Opioids and social bonding: Effect of naltrexone on feelings of social connection and ventral striatum activity to close others. Journal of Experimental Psychology: General 2019; 149:732-745.

76. Inagaki TK, Ray LA, Irwin MR, Way BM, Eisenberger NI: Opioids and social bonding: Naltrexone reduces feelings of social connection. Soc Cogn Affect Neurosci 2016; 11:728-735.

77. Morris MS, Domino EF, Domino SE: Opioid modulation of oxytocin release. J Clin Pharmacol 2010; 50:1112-111

78. Tuominen L, Miettunen J, Cannon DM, Drevets WC, Frokjaer VG, Hirvonen J, et al.: Neuroticism associates with cerebral in vivo serotonin transporter binding differently in males and females. Int J Neuropsychopharmacol 2017; 20:963-970 
79. Spies M, Knudsen GM, Lanzenberger R, Kasper S: The serotonin transporter in psychiatric disorders: insights from PET imaging. Lancet Psychiatry 2015; 2:743-755

80. Kambeitz JP, Howes OD: The serotonin transporter in depression: Meta-analysis of in vivo and post mortem findings and implications for understanding and treating depression. J Affect Disord 2015; 186:358-366 
Figure 1. Mean binding potential maps for $\left[{ }^{11} \mathrm{C}\right]$ carfentanil and $\left[{ }^{11} \mathrm{C}\right] \mathrm{MADAM}$. 
Figure 2. Brain regions where the level of $\left[{ }^{11} \mathrm{C}\right]$ carfentanil was higher in participants with secure versus insecure (i.e. anxious or avoidant) attachment. The data are thresholded at $p<.025$, FDR corrected. 
Figure 3. Box plots of distributions of regional binding potentials for $\left[{ }^{11} \mathrm{C}\right]$ carfentanil (left) and $\left[{ }^{11} \mathrm{C}\right]$ MADAM (right) for the securely and insecurely (avoidantly or ambivalently) attached subjects. Dots show outliers ( $>1.5$ times the interquartile range). Significant between-group differences are marked with asterisks. 
Table 1. Demographics of the study population $(\mathrm{N}=39)$. 
Table 2. The results of variance analyses, when investigating the differences between participants with secure and insecure attachment (avoidant or ambivalent attachment) in binding potentials for $\left[{ }^{11} \mathrm{C}\right]$ carfentanil and $\left[{ }^{11} \mathrm{C}\right]$ MADAM in the ROIs. 


$$
x=-3
$$

$$
y=-6
$$
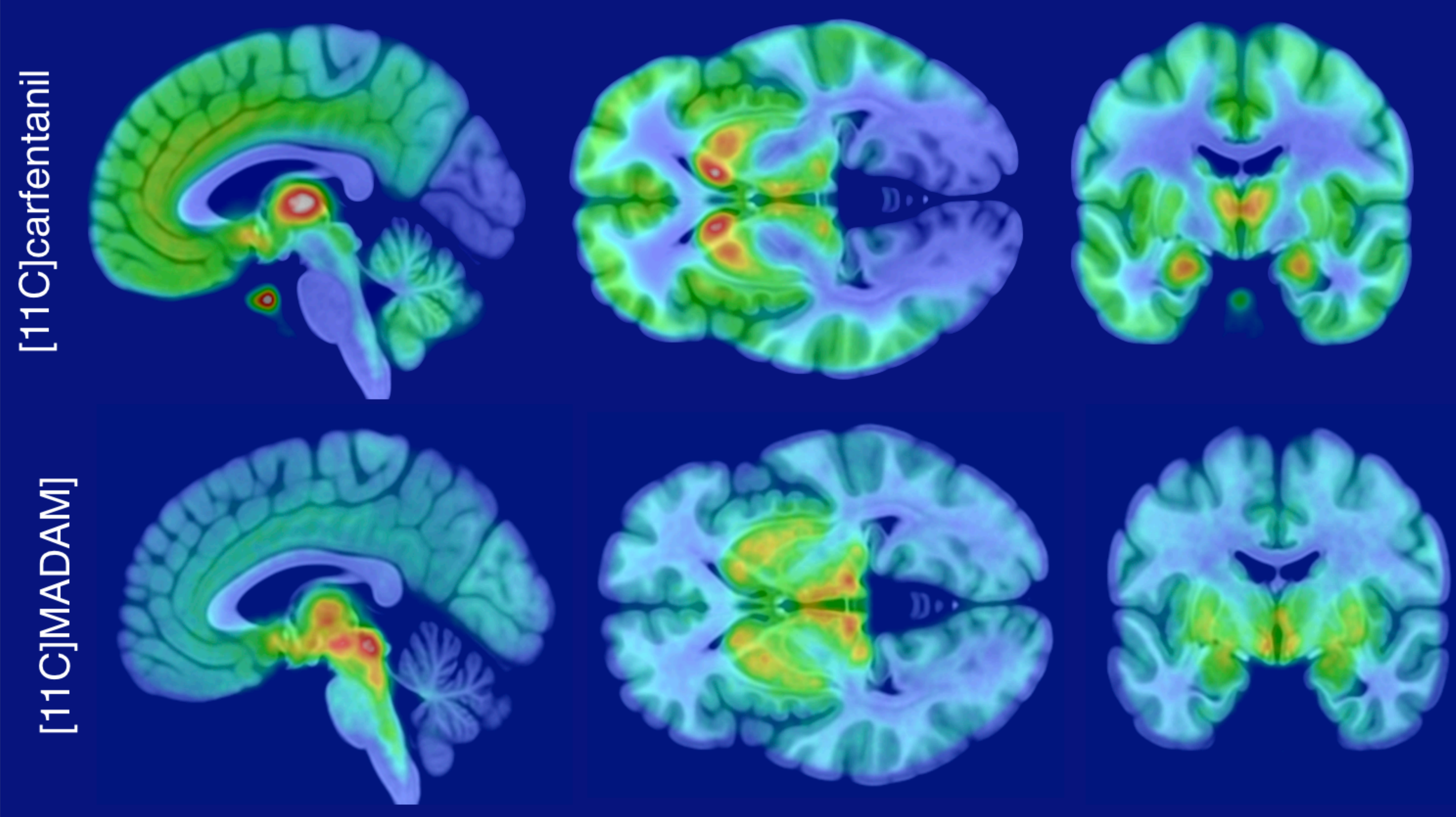

3.5

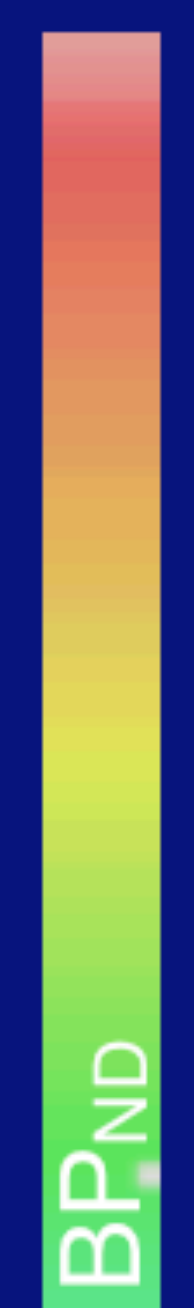


$y=-26$

$$
x=-17
$$$$
z=-14
$$

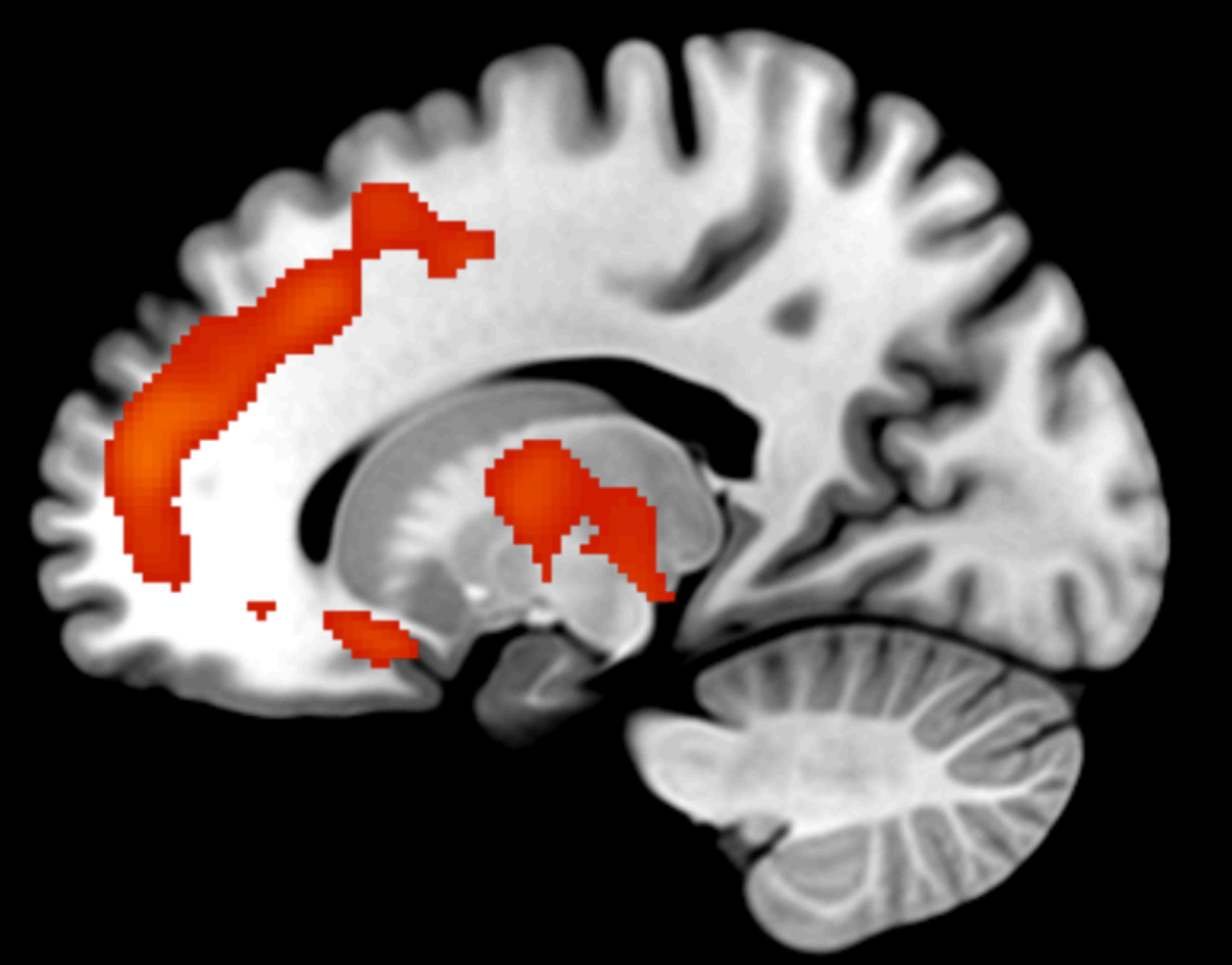

FDR

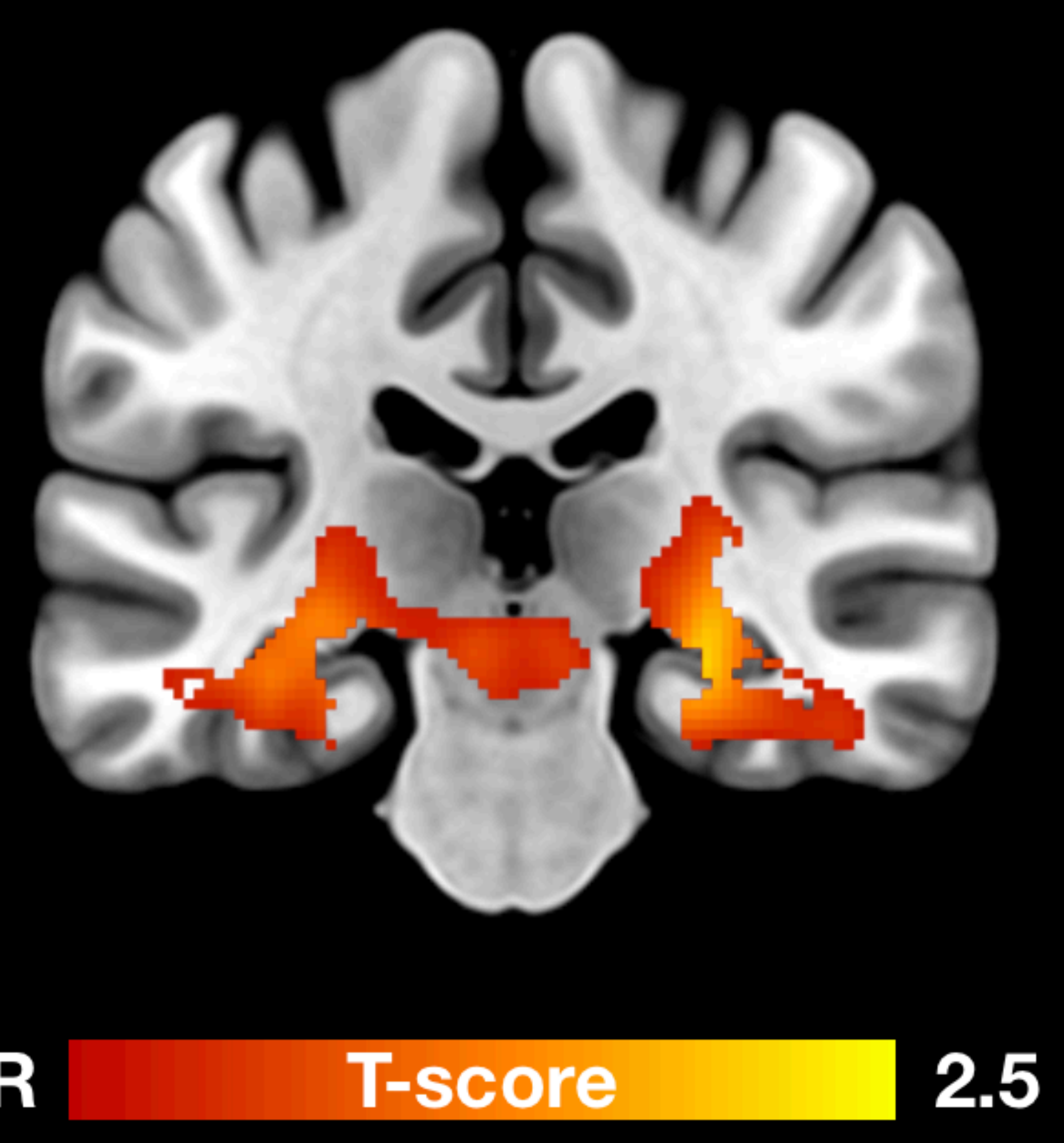



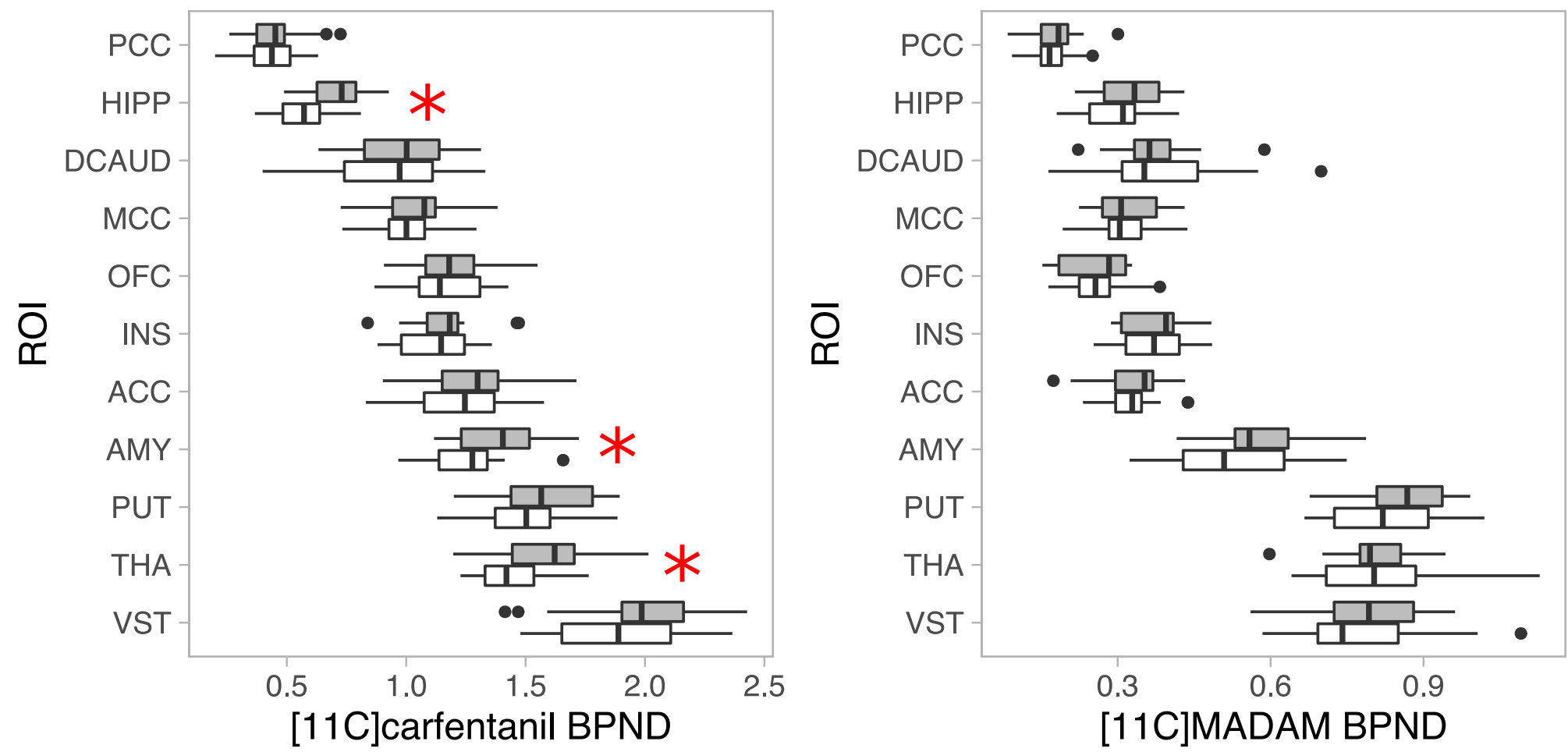
Supplementary Material 1. Additional information about the DMM.

The DMM divides the attachment strategies in categories by the way the subject processes the information related to attachment. The DMM evaluates the processing of cognitive/affective information as well as the accuracy (vs. biases) of information processing. Further, the DMM pays particular attention on "self-protective strategies" (that regulate one's information processing concerning attachment) and on "reorganization" (i.e. the process where an individual actively changes his/her representation of the past and present experiences). When compared to other coding schemes of the AAI, the DMM has a stronger emphasis on more complex attachment styles associated with a greater distortion of information. The DMM includes a more sophisticated set of attachment styles that differ from each other also by quality (not only by quantity such as in some continuous measures of attachment). 


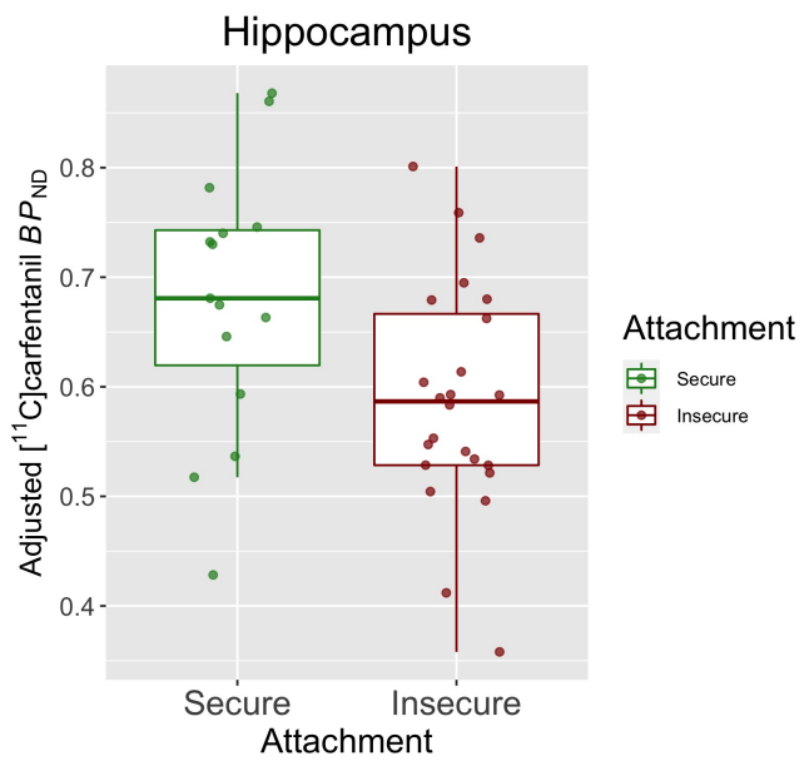

Supplementary Figure 1. Secure attachment associates with higher $\mu$-opioid receptor availability in the hippocampus after correcting for age and sex (beta $=0.117, \mathrm{t}_{35}=2.82, \mathrm{p}=0.0079$ ). 